\title{
Learning Communities: A Business School Perspective
}

Kelly Hartnett, (E-mail: Kelly_Hartnett@uncg.edu), University of North Carolina, Greensboro Stephen R. Lucas, (E-mail: srlucas@uncg.edu), University of North Carolina, Greensboro Benton E. Miles, (E-mail: bemiles@uncg.edu), University of North Carolina, Greensboro John R. Sopper, (E-mail: jrsopper@uncg.edu), University of North Carolina, Greensboro

\begin{abstract}
This paper discusses the organization and operation of a university learning community program at the University of North Carolina at Greensboro (UNCG). After several years, the program administrator and certain of the faculty and staff reflected on the achievements of the program. The learning community concept is discussed as well as the nature of the learning activities both general and those specific to the business school. The program reported higher levels of student retention and students reported higher involvement in leadership skill development and the UNCG community than students who were not in the learning community program.
\end{abstract}

\subsection{Introduction}<smiles>[AlH2]</smiles>

ix years ago, the University of North Carolina at Greensboro (UNCG) embarked on a program to establish learning communities and to add a residence feature which resulted in a living and learning arrangement. Sufficient time has passed so that a reflection on the accomplishments will be beneficial to the campus community and to the larger audience of participants in this nationwide trend as well as those anticipating establishing such a program for the first time. This paper will discuss the overall view of the learning community concept as well as the details of structuring one in a business school.

\subsection{What is a Learning Community?}

The learning community (LC) concept is not new; the concept is to organize a small community of students with a common focus such that the students become an effective team that supports and encourages the academic success of its members. The goals different institutions seek to accomplish by means of learning communities vary, but some commonly shared goals are as follows: to improve student academic success, build a sense of community and institutional loyalty on large and diverse campuses, initiate students into the academic culture and values, to provide faculty and staff with meaningful teaching experiences, and to improve student retention and graduation rates.

"What works in general in undergraduate classrooms also seems to work in learning communities: high degrees of student involvement and active learning, engagement of students in ideas and projects that are personally meaningful, high expectations of student work, and timely and detailed feedback on that work." ${ }^{1}$

"These programs work when both faculty and students pay attention to both the academic and social connections that the learning community structure invites. They work best when there are explicit efforts at integration and synthesis relative to program themes, and careful attention to building community in terms of inclusion, communication, participation, responsibility and reflection on the part of all learners. ",

The LC program, in general, allows students to develop a learning context in their quest for knowledge. LC programs for first-year students exist at all Carnegie Classifications (Research Extensive Universities, Research

\footnotetext{
${ }^{1}$ MacGregor, 1994

${ }^{2}$ MacGregor, 1994
} 
Intensive Universities, Masters I and II Institutions, Baccalaureate - Liberal Arts Colleges, Baccalaureate - General Colleges, and Associates Colleges). ${ }^{3}$

\subsection{Ione Grogan College at UNCG- the Specifics of the Program}

The Ione Grogan College (both a residence hall and the title used to identify the LC program were named in honor of Ms. Ione Grogan, an alumna of UNCG, who once served as a counselor at UNCG) is UNCG's Freshman Living/Learning Communities Program. In the Grogan Learning Communities Program, a learning community is comprised of a group of freshmen students (ten to twenty-two) who have selected a topic of interest from the menu of learning community topics offered by the program during the year a given student applied for admission. Learning community topics are determined by the faculty who agree to design and offer a learning community in any given year as well as by the offerings and requirements of the University's curriculum. Some learning community topics reflect the general education requirements at UNCG, while others relate primarily to a particular major or professional school such as nursing, education, and business. Prospective students learn about the program's offerings and potential benefits through various recruitment and admissions efforts as well as the University's Home Page. Interested students who have been admitted to UNCG must then elect to apply for admission to the learning community of their choice on a separate application that is sent directly to the learning community program administrator. Not all of the entering freshmen at UNCG are in a learning community; rather, the LC participants are interested freshmen who voluntarily self-select to be part of the program.

The LC is structured so that its common cohort of students will bond. The students in each LC take a course or two together, live in the same residence hall, meet as a group with a faculty mentor, and participate in a variety of activities (social and academic) designed for beginning students. The overall intention of the LC is to build "community" among the students and faculty. The learning communities serve as a reference group for the students and provide these students with a small community within the UNCG, 14,000+ student population in which each LC student is intimately familiar and at ease in that setting. As is true of many of the learning community programs that exist throughout the United States, the program at UNCG was designed to enhance student success. UNCG added the important goals of helping to retain students and strengthening the sense of institutional identity and loyalty among the student body.

In addition, in UNCG's program, certain upper-class students are assigned as Peer Academic Leaders (PALs) to each LC. Each PAL applied for assignment to a learning community and passed through a rigorous interview and selection process. PALs assist the faculty members (referred to as Faculty Fellows) in planning and conducting the learning activities of the LC and they are available to the students in their LC to provide peer mentoring and guidance. They also organize outings and social and academic gatherings. There are several reasons that the upper-class student may be motivated to apply for the position of Peer Academic Leader: the student receives a stipend plus a reduced cost for campus lodging and the PAL is presented with excellent leadership opportunities.

For most of the students in the LC program at UNCG, one of the common courses they take with their LC is a one- credit orientation and basic skills course called "The Learning Community Experience." The purpose of the course is to enhance and more intentionally structure the efforts of the Grogan College Learning Communities Program; this course is vital to implementation of the learning community concept. The course integrates topics with the learning community focus on intellectual community building, faculty mentoring, fostering student ownership and responsibility, critical reflection, interdisciplinary collaboration, "co-learning," and the cultivation of a shared culture (both intellectual and professional) within the university. By providing a planned and structured framework built into the students' class schedules and linked to the University's curriculum, the faculty, students, and staff can more effectively work together to counter the forces of fragmentation, build engaged intellectual communities, realize key university values, and support student success. ${ }^{4}$

\footnotetext{
${ }^{3}$ Learning Communities Project [http://learningcommons.edu/]

${ }^{4}$ Hill 1985
} 


\subsection{General Activities for all UNCG Learning Communities}

There are a myriad of activities in which all the LCs participate. Some of those activities are as follows:

A. Learning about leadership and team work.

B. Learning styles assessments.

C. Study skills and time management workshops at the Learning Assistance Center.

D. Library tours and workshops on research.

E. A Career Services program series on resume` preparation, interviewing principles, preparing a cover letter, and networking.

F. Attending University Concert and Lecture Series offerings.

G. A Wellness Center program series on a variety of topics such as sexually transmitted diseases; stop smoking; healthy relationships; breast cancer awareness; nutrition, alcohol, and drug abuse.

Examples of other activities of LCs are as follows: diversity workshops offered by the Anti-Defamation League and UNCG's Office of Multicultural Affairs, participation in the Grogan College Co-op (a student run, events planning and activities board), and interdisciplinary learning community collaborations in which students from several LCs work together to research and present an academic topic of mutual interest. The goals that permeate all of the activities are career and academic advising, diversity, leadership, study skills, team building, and wellness.

The budget for such an undertaking can be accomplished for $\$ 80,000$ per year. This figure includes a program administrator's salary, Faculty Fellow stipends, PAL stipends, a graduate assistant, office expenses, and the cost of activities for each LC (about $\$ 250$ for each LC). (A co-worker with the administrator is paid separately by the Housing and Residence Life Office.)

\subsection{Common Learning Community Topics at UNCG}

While topics in the UNCG Program change depending on faculty interest and participation, the list below presents the sorts of topics that have typically been offered since the inception of the LC Program.

1. Music, Mind, and Motivation: A Community of Performing Musicians: If you are a music major admitted to the widely acclaimed UNCG School of music, then take advantage of this very special opportunity available only to entering freshmen in the school of music. Join with fellow music majors and one of our faculty artists from UNCG's School of Music and share in special activities, exciting outings, intense discussions, lectures, concerts, and visits from professional musicians and others who make their career in the arts.

2. Blacks in America: A Faculty Fellow from the African-American Studies Program and the English Department at UNCG takes you through a dramatic encounter with the struggles, accomplishments, and contributions of Africans and their diverse descendents in America.

3. Exploring Human Diversity: In this learning community, students pay particular attention to the varieties of symbols, customs, values, and ideals that shape and guide the actions and attitudes of different people from diverse cultural backgrounds. You will meet, interview, and interact with UNCG students who are visiting from abroad, attend international festivals and programs, dine on a variety of different foods, ponder and discuss the complexities of cross-cultural understanding, and learn more about yourself and your own background in the process!

4. Exploring Teaching as a Profession: The purpose of this learning community is to offer students interested in teaching a way to find out if teaching is right for them. Through visits to area schools and workshops with UNCG education faculty, students will gain valuable insight into the teaching profession.

5. Finding Your Focus: Not sure about where you are heading, your major, future career, or what college has to offer? Maybe too many things interest you and you are not sure which direction to choose? Does college seem a bit confusing and maybe even scary? Afraid you will make a big mistake? Then this learning community is for you! Join with other similar students to explore career and educational options, discuss 
plans and paths in life, identify values, and learn more about how and why a college education can contribute to your overall happiness. Also, develop practicing skills (research, writing, interviewing, and presenting) that are useful to everyone and required in many other classes at UNCG. This is a valuable opportunity to get personalized coaching, encouragement, and useful training that will help you in college and beyond.

6. Health and Wellness: Through formal course work in public health education, hands on participation in the programs offered by the UNCG Wellness Center, and active involvement in health and wellness presentations, students in this learning community learn about how to live well and stay healthy, acquire important teaching and presenting skills, become certified as peer health educators, and explore career opportunities in a variety of healthcare fields

7. Magic of Disney: Have you ever been frustrated by red tape, put on hold for an eternity, or been given the run around? Have you ever wondered why it is so difficult to get your simple questions answered or searched in vain for the person with the solution to your problem? Have you ever thought that there has got to be a better way or how you could do a better job? If so, welcome to the Magic of Disney learning community where you will be introduced to the cutting-edge organizational expertise, customer service success, and hospitality magic of the Walt Disney World Company through course work, field trips, and hands-on learning activities. In addition, by using the Disney's worldwide expansion and leadership position as a case study, students will learn how to use fundamental skills and proven strategies for relating to people, communicating effectively, solving problems creatively, stimulating the imagination, and building strong organizations that work.

8. The Nursing Profession: Nursing is a very important and rewarding field, but also a demanding one requiring intensive preparation and professional development. The Grogan learning communities program and the UNCG School of Nursing are seeking to develop a learning community specifically tailored to prenursing majors.

9. On Stage - A Community of Visual and Performing Artists: Can you dance, sing, or play an instrument? Maybe you just want to direct those who do - then join your fellow performing artists and our Faculty Fellow from the Dance Department for an adventure in multimedia collaboration and production.

10. Playing Shakespeare: In this living and learning community we perform our way into the depths of the human drama and follow the lead of that great poet of the human passions, William Shakespeare.

11. Taking Care of Business: Considering a major in business? Take a guided tour of the business world with Faculty Fellow Bud Miles, one of our experts from the Bryan School of Business and Economics. Meet interesting and successful people who are starting their own businesses, network, explore opportunities, and learn first-hand about business success and entrepreneurship.

\subsection{The UNCG Business School Learning Community}

In addition to the integrated activities of the Grogan College and the learning community as whole, each LC structures learning activities of its own. Below are some of the activities of the business learning community.

1. Several guest speakers were solicited for the business LC. Examples of guest speakers are as follows:

A. Executives from United Way talked about civic responsibility of the business community and developing a social conscience. One of the themes - it is the responsibility of business people to "give back." One of the speakers was a recent UNCG graduate.

B. A WDW recruiter for the Disney College Program spoke on the value of internships and explained the potential gain in the future as a result of an internship.

C. A Disney faculty member spoke on customer service and leadership.

D. A trainer from the Center for Creative Leadership spoke on the subject of personal growth and opportunities that will be available while at UNCG. The Center is an international training center. The speaker was obtained through a connection with a member of the Advisory Board of the Bryan School of Business and Economics at UNCG.

2. One out-of-class activity was the Greensboro United Way Kickoff which took place at the UNCG ballpark. This was an opportunity to meet community leaders in an informal setting. 
3. A second out-of-class activity was a visit to the Nussbaum Center for Entrepreneurship. The Center is a small business incubator; it has been deemed as the most successful incubator in North Carolina. A presentation was made by the Associate Director of the Center. The students toured the incubator and talked, in depth, with three of the business owners. The three businesses were a Spanish Internet station, a music company, and a golf club manufacturer that has developed a new putter that it claims will revolutionize golfing (the putter improves the putting ability of the average golfer, which in terms of importance in North Carolina, is next to solving world hunger).

4. A third out-of-class activity was a visitation to a business that operates a haunted house. While there, the owners spoke to the students about the business-end of a haunted house and told them that they were presently negotiating with a contact to build three haunted houses in England. One of the owners is a UNCG graduate who majored in theater. He spoke to the students about the importance of taking business classes, regardless of one's major.

5. Another out-of-class activity was a social get-together at a restaurant. If there is a free, non-pizza meal at a restaurant, there will be close to $100 \%$ participation and this activity will receive the highest percentage of participation of any activity.

\subsection{The Challenges}

"The learning community idea is simple to conceive of, but actually complex and demanding to carry out. Whether learning communities are in their earliest experimental phase on a campus, or are becoming predictable features of the curriculum, they face continuous challenges. " 5

“There's no question that such programs require extensive, collaborative planning and conscientious work." "This means making continuous efforts to attract faculty members new to learning communities..." "No matter what scale they take, healthy learning community efforts must have a clear rationale in terms of their curricular purposes and student clientele, and in terms of the larger curricular landscape of the campus. "6

Administrative challenge: Like many other learning community efforts, especially those with a residential component, the UNCG program attempts to integrate faculty, academic courses, co-curricular activities, social events, and housing into a package that creates a rich and supportive environment for students To be successful, those who administer the program must work closely and continuously with a wide range of institutional units and constituencies. "Administratively, learning community structures call for communication and collaboration across many campus units. Deans and division or department chairs, librarians, admissions recruiters, academic advisers, the registrar, designers of the course schedule, schedulers of classroom space, residence life staff, service learning offices - all might be involved at various stages of learning community planning and implementation. Whether learning communities are just starting on campuses or long established, these programs are almost always unfamiliar to students and go against the grain of established procedures. Therefore, healthy learning community enrollment depends critically on academic advisers and savvy ways of marshaling appropriate administrative support."7 Moreover, those programs like UNCG's that specialize in the critical first year have the added administrative tasks associated with recruiting, advising and registering students while they are still seniors in high school.

Assessment challenge: "What distinguishes learning communities as an innovation is their great flexibility. They present a structure that teachers can take in myriad directions to engage different student audiences, to examine academic content and issues from a variety of perspectives and to realize diverse educational goals." "Assessment must play a critical role in understanding and improving learning communities. Just as there is no single learning community model, there is no single approach for meeting these challenges." ${ }^{\circ}$ In the end, each campus must address its needs in its own way. At UNCG, increased awareness of the unique and complex nature of the Grogan Learning Communities Program has led to a further recognition that the University's existing and standard assessment instruments may not be adequate for capturing what is happening in the LCs. This in turn has led to the hiring of

\footnotetext{
${ }^{5}$ MacGregor, 1994

${ }^{6}$ MacGregor, 1994.

${ }^{7}$ MacGregor, 1994.

${ }^{8}$ MacGregor, 1994
} 
additional assessment experts assigned specifically to the special academic programs like the LCs. It has also led to discussions and initial efforts aimed at designing assessment instruments specifically for the learning communities. For example, the need has been seen to better identify the specific outcome for students that each element of the program is intended to provide, and the ways to assess whether a given element (e.g., Faculty Fellow, PAL, common academic course, the Learning Community Experience course, the Grogan Co-op, the various co-curricular activities and workshops as well as the residence hall itself) effectively accomplishes its specific outcome.

\subsection{The UNCG - LC Results}

Available data regarding the success of the program is generally positive. Students in the LC program, when compared to non-LC students living in residence halls without such a program have a higher retention rate, express a higher degree of positive identification and overall satisfaction with the institution, and respond very favorably that they have developed leadership skills and have been involved in rewarding service activities both within and beyond the UNCG community.

For example, LC students who entered as freshmen in 2000 are currently juniors. Recent data comparing the retention of LC students through to their third year showed that $58 \%$ were still fully enrolled at UNCG after three years as compared to $55.4 \%$ of those students not enrolled in the LC or a similar program at UNCG. The retention picture for these students is even better when the predicted GPA for the Grogan LC students is compared to that of the other freshmen entering in 2000 who were NOT enrolled in an LC program. The Predicted GPA for the Grogan LC students as a whole was 2.58 - the lowest cohort at UNCG. The Predicted GPA for the other nonparticipating freshmen who entered in 2000 was 2.65. The Grogan LC students entered with a lower predicted GPA yet were more likely to be enrolled in the junior year than were those students not participating in an LC program. Available data for students entering in 2001 and 2002 are similar. LC students were retained at a higher percentage than students not participating in any LC type program, even when the cohort of non-participating students entered with a higher predicted GPA than those who elected to participate in the LC program.

More qualitative results are similarly encouraging. According to UNCG's most recent "Spartan Experience Questionnaire," LC students from the 2000, 2001, and 2002 cohorts were more likely (by more than ten percentage points) to rate UNCG Excellent or Good in the category of "Student-Faculty" interaction than were those students not participating in any LC or similar program at UNCG.

However, in other assessment categories, such as Actual GPA and some of the qualitative and experiential areas, the positive results are inconsistent (positive one year and negative the next year) from year-to-year. These are subjects for concern and more study of these areas is planned.

Still, the results of the UNCG LC program are positive in some key areas, such as retaining more of those students who are most marginal in terms of both their Predicted GPA and their Actual Achieved GPA, creating a sense of community support, and providing for more faculty and student interaction. The recommendation is to continue the program but with more emphasis placed on the evaluation aspects.

The UNCG program has operated much like other learning community programs. While it is recognized that LC programs will differ from campus to campus, the basic learning community concept responds to the problems of fragmentation on campuses by bringing people together, both inside and outside of the formal classroom, and involving them in activities with a common purpose. The UNCG faculty, students, and staff involved in the LC program came together in small academically-intensive groups centered on shared concerns and topics.

\subsection{Other Results: Faculty and Staff Involvement and Sense of Satisfaction}

The Faculty Fellows turnover in the three-year period is approximately 50\%. Some Faculty Fellows have been involved for the life of the program while others will be new to the program next fall. With the need for faculty to be concerned with research, teaching, and service efforts, turnover is expected. An attempt is made to motivate the faculty member to the point of participation in the LC program. Each Faculty Fellow receives $\$ 3,000$ as 
compensation for participation in the LC program which means he/she sponsors a special interest LC, attends several whole-group functions of the LC program, and is responsible for conducting a one semester-hour class. This money can be used for a one-time salary increase or travel, in lieu of salary. (The Faculty Fellow will have access to more of the same amount of money if he/she defers it as salary and, instead, applies it toward travel expenses.)

The LC program is a good opportunity for a faculty member. Many faculty members are known to voice the reason for selecting to be a member of a university faculty as the desire to develop relationships with young people and to make a contribution in their development. The LC program offers the Faculty Fellows the opportunity to develop a close relationship with a small group of students. For the faculty who are teaching distance education classes or large-enrollment classes, the intimacy of the learning community is refreshing.

Similar opportunities for meaningful work and professional development are afforded to Student Affairs staff and other support staff through the learning community program. Learning Communities are an opportunity for support staff to develop, implement, and refine co-curricular programs and to participate in mentoring and advising students. The LC Program also affords opportunities for those who do not teach, to connect more directly to the institution's central mission. For example, in tandem with the development of the LC program, the Office of Housing and Residence Life at UNCG re-wrote the job description for the residence directors so as to emphasize educational programming, academic advising, and student mentoring. The new job description is reflected in the job title, Coordinator of Residential Learning; these staff positions now involve a much greater degree of contact with students in relationship to each student's academic success.

Participation by the LCs in the Building Bridges Program provides another example. Building Bridges is a three part series of diversity workshops created by the Anti-Defamation League and offered to faculty and staff through UNCG's Office of Multicultural Affairs. Building Bridges was initially conceived as a training program for faculty and staff. But when some of the LCs elected to participate, Building Bridges became an opportunity for staff members (non-faculty) from across the University to work in common with students. The results were that staff members were able to do things that the faculty could not do, namely, bring to bear on the student's experience the perspective of those who were doing diversity training, not as a school assignment, but as part of an effort to perform more effectively at their "real-world" jobs. Students in the workshops expressed initial apprehension about being in a situation with older, working adults. But afterwards, students and staff alike found the experience more meaningful than it would otherwise have been. For the staff, there was the opportunity to speak to students and show them how staff members (non-faculty) can play a role in the academic enterprise and can care deeply about it. Students were better able to see "real-world" applications of the issues and skills presented in the workshop series. This is but one example of the way that learning communities overcome fragmentation at larger institutions, build community, and successfully initiate students into the University's academic culture.

\subsection{Summary}

Retention is the major concern for many universities. The LC Program's effectiveness should be recognized by universities as an effective tool to help retain students and to achieve other desirable goals. Of critical concern in the implementation of such a program is the need for special tribute to the LC faculty and staff; they should be rewarded and acknowledged for their participation.

\subsection{References}

1. Hill, Patrick. October 22, 1985. The rationale for learning communities. Address presented at the Conference on Learning Communities of the Washington Center for Improving the Quality of Undergraduate Education.

2. Learning Communities Project. Retrieved November 15, 2003, from [http://learningcommons.edu/].

3. MacGregor, Jean. Spring, 1994. Learning communities taking root. Washington Center News. Retrieved November 15, 2003, from [http://learningcomons.evergreen.edu/pdf/spring1994.pdf].

4. Sopper, John R. Ione Grogan College Learning Communities Program, 2003 
$\underline{\text { Notes }}$ 